\title{
Mesane Taşlarının Perkütan Minimal İnvazif Tedavisi
}

\author{
Erkan Erkan, Uğur Yücetaş, Vural Saçak
}

İstanbul Eğitim ve Araştırma Hastanesi, Üroloji Kliniği, İstanbul

Giriş iner sistem taşlarının \%5'ini oluşturan mesane taşları, çoğunlukla alt üriner sistem obstrüksiyonu, tekrarlayan üriner enfeksiyonu ve nörojenik mesane disfonksiyonuna bağlı olarak oluşur (1). Oluşum yeri ve mekanizmaları da göz önüne alınarak mesane taşları genel olarak primer veya sekonder olarak sınıflandırılır. Az gelişmiş ülkelerdeki çevresel, iklimsel ve beslenme alışkanlıklarına bağlı olarak endemik bir sorun iken, gelişmiş toplumlarda daha sıklıkla 50 yaş üstü erkeklerde BPH'ya eşlik eden bir durum olarak karşımıza çıkar. Taş hastalığının genel doğası ve predispozan faktörleri nedeni ile mesane taşlarının da tekrarlamaya eğilimli olduğu bilinmelidir.

Tedaviye yönelik olarak ilk hedef hastanın taştan arınd1rılması olsa da; altta yatan sebebe yönelik yaklaşım büyük önem taşır. Kemolizden açık cerrahiye kadar tedavi seçenekleri mesane taşı tedavi skalasında yer alır. Girişimsel tedavi seçenekleri; endoskopik sistolitotripsi (mekanik, elektrohidrolik, ultrasonik, lazer), perkütan ve açık sistolitotomi olarak sıralanabilir. Günümüz modern yaşam temposu ve teknolojik gelişmelerin eşliğinde mesane taşlarına yönelik tedavi yaklaşımı giderek minimal invazif yöntemlere doğru kaymaktadır. Bunun yanı sıra tedavi seçiminde; hastanın anatomik özellik ve komorbiditeleri, taşın bileşim ve büyüklüğü ile diğer olası hasta ile ilişkili risk faktörleri göz önüne alınmalıdır. Günümüzde mesane taşlarının çoğunluğu transüretral sistolitotripsi ile fragmante edilerek tedavi edilmektedir. Ne var ki; diğer transüretral cerrahi yaklaşımlarda olduğu gibi, bu yaklaşımın uretral hasar ve sonrasında darlık oluşturma riski vardır. Özellikle büyük veya çok sayıda mesane taşı olan hastalarda cerrahi süresinin uzaması veya üretral kan akımını bozacak şekilde geniş lümenli şaft ve endoskopların kullanılması bu riski artırır. Bu durum orta ve uzun dönemde üretral darlığa ve fasit bir daire şeklinde staz ve sekonder mesane taşlarına yol açabilir. Bu durumu engellemek ve uretral hasarı asgariye indirmek için mesane taşına perkütan yolla yaklaşım uygun durumlarda akılcı bir yaklaşımdır. Perkütan girişim üretral yolun asgari oranda kullanılmasını sağlarken özellikle büyük veya çoklu taşların temizlenmesi için güvenli, geniş bir çalışma traktı sağlayacaktır. Günümüzde belli bir standart uygulama alanı ve metodu oluşturulan perkütan sistolitotripside böbrekteki perkütan girişe benzer şekilde kontrast madde ve serum fizyolojik ile doldurulan mesaneye ultrasonografi veya floroskopi eşliğinde $18 \mathrm{G}$ iğne ile giriş yapıldıktan sonra kılavuz tel yollanması ve dilatasyon sonrası Amplatz kılıf yerleştirilerek nefroskop ile uygun enerji kaynağ1 veya grasper/basket kateterler ile taş temizlenmektedir.

$\mathrm{Bu}$ makalede kliniğimizdeki perkütan mesane taşı tedavi deneyimimiz çeşitli modifikasyon ve öneriler eşliğinde detaylandırılmaktadır.

\section{Hasta Grubu}

Son 3 yıl içinde, çapı $3 \mathrm{~cm}$ 'den büyük tek veya çok sayıda mesane taşı olan ve açık tedavi adayı olan 17 hasta bu yaklaşım ile tedavi edildi. Hastaların yaşı 53 ila 83 arasında idi. Hastalardan ikisi daha önce açık sistolitotripsi, biri ise açık prostatektomi operasyonu geçirmişti. Hematüri, tekrarlayan üriner sistem enfeksiyonu veya alt üriner sistem semptomları ile polikliniğimize başvuran hasta grubuna, öncelikle üriner ultrasonografi ve devamında düz karın grafisi, IVP veya kontrastsız BT ile tanı konuldu. Üriner sistem enfeksiyonu varlığında kültür ve antibiyograma uygun antibiyotik tedavisi ile idrarı steril hale getirilen hastalar cerrahi tedavi amacı ile yatırıldı.

\section{Preoperatif Hazırlık}

Operasyon öncesi herhangi bir barsak temizliği önerilmemekle birlikte operasyondan önceki gün sıvı ağırlıklı beslenme hastada postoperatif rahatlık sağlayacaktır. Aspirin ve diğer nonsteroidal analjezikler operasyondan bir hafta önce kesilir ve derin ven trombozu riski olanlara düşük doz heparin başlanarak antiembolik çoraplar giydirilir. Preoperatif idrar kültürüne bağlı olarak antibiyotik profilaksisi düzenlenir.

\section{Anestezi ve Hasta Pozisyonu}

Gerek rejyonel, gerekse genel anestezi hastanın komorbiditelerini ve anatomisini göz önüne alarak tercih edilebilir. Hasta süpin pozisyonda yatarken, yarı litotomi pozisyonuna getirilecek şekilde ayaklar yana doğru açılır ve altlarına yumuşak destek konularak sabitlenir. Burada özellikle midüretral askı ameliyatlarındakine benzer şekilde tam veya abartılı litotomi pozisyonunun verilmemesi hem önden; hem de yandan mesane ve üretraya hâkimiyet sağlayacaktır. Uygun alan temizliğini takiben sistoskopiyi ve alt abdominal bölgeye yaklaşımı engellemeyecek şekilde hasta örtülür. Üst kısım için yapışkan su geçirmez örtülerin kullanılması özellikle ameliyatın ileri kısımlarında sahanın ıslanmaması adına önerilir. 


\section{Cerrahi Teknik}

Öncelikle $17 \mathrm{Fr}^{\prime}$ den daha kalın olmayan bir sistoskop ile üretrosistoskopi yapılır. Eşlik edebilecek mesane çıkım obstrüksiyonu, üretra darlı̆̆ı ve mesane içi patolojilerin gözlenmesinin yanı sıra mesane taşlarının sayı ve büyüklüğü belirlenir. Optimal hizla mesane doldurulduktan sonra perkütan girişim yer seçimi için mesane ön duvarı gözlenir ve transilüminasyon ile hemorajiye sebep olabilecek vasküler yapılar belirlenir. Sistoskopun sağladığı transilüminasyon ile avasküler bölgeden pubisin yaklaşı 1,5-2 $\mathrm{cm}$ süperiorunda cilde $1 \mathrm{~cm}$ 'lik transvers insizyon yapılır. Sivri uçlu yeniden kullanılabilir veya tek kullanımlık 10 veya $12 \mathrm{~F}$ laparoskopik trokar ile 90 derecelik açı ile kontrollü olarak hafif basınç uygulayarak mesaneye girilir (Resim 1,2). Bu giriș sırasında video-sistoskopik görüntü ile girişin mesanenin avasküler kısmından olması sağlanırken aynı zamanda derinlik kontrolü yapılır (Şekil 1). Bu sırada gerekli bağlantıları ile birlikte perkütan müdahale için rijid nefroskop hazırlanır ve trokar mandreni alınır alınmaz trokardan içeri sokularak mesaneye

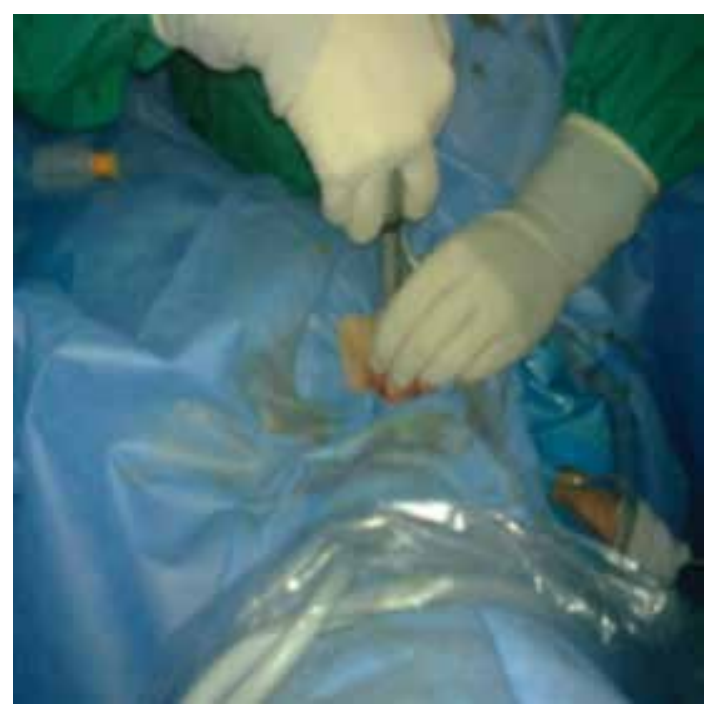

Resim 1: Trokarla mesaneye giriş

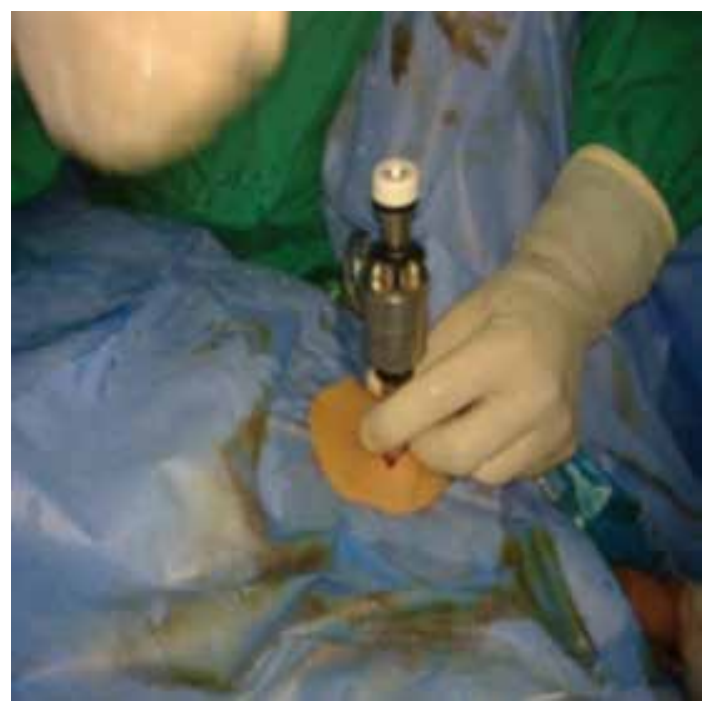

Resim 2: Trokar pozisyonu

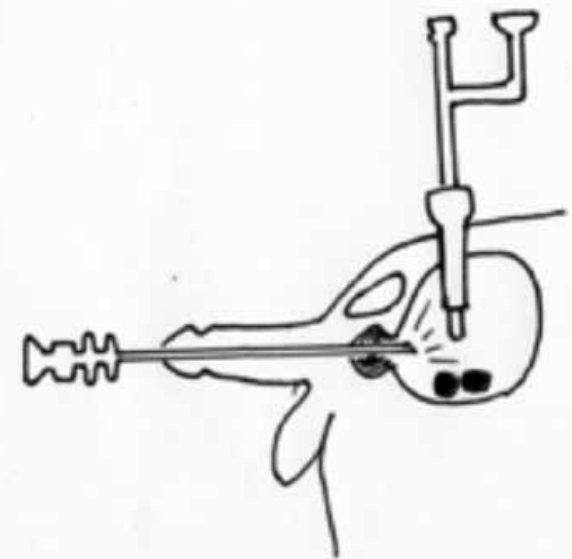

Şekil 1: Sistoskopik kontrol altında mesaneye giriş

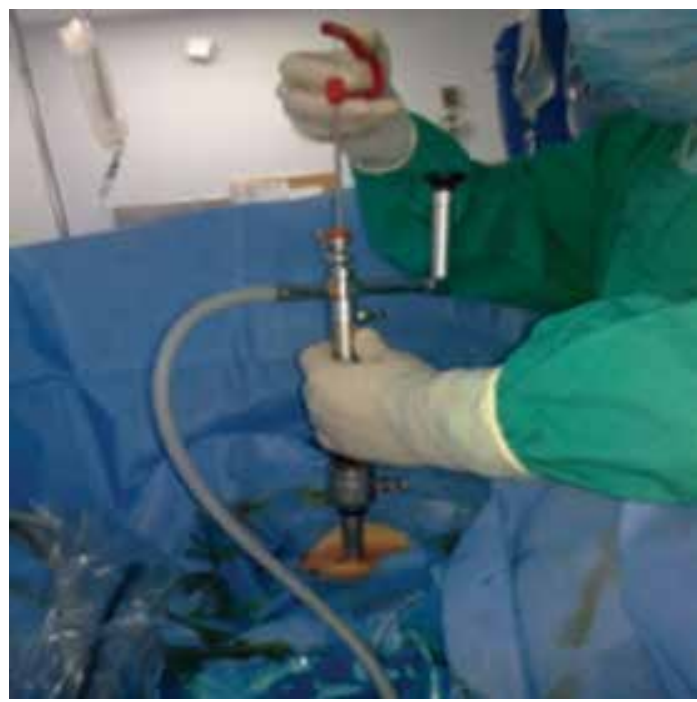

Resim 3: Mesaneden basket ile taş alınması

girilir (Resim 3). Giriş sırasında "yivli trokar" kullanılması başta girişte biraz zorluk yaratsa da operasyonun devamında trokarın stabil kalması adına kolaylık sağlayacaktır. Nefroskop ile giriş yapıldıktan sonra mesane içindeki taşlar eğer çok sayıda ve küçük çaplı ise direkt olarak tripod veya benzeri taş ekstraksiyon aletleri ile dışarı alınır (Resim 4, Şekil 2). Eğer çapları trokardan çıkabilecek kadar küçük değilse eldeki enerji kaynağına göre pnömatik, ultrasonik veya lazer yöntem ile disentegre edilerek taşlar temizlenir. Yöntemin amacına yönelik olarak, taş parçalarının kısa zamanda çıkabileceği çalışma kanalı büyüklüğünün sağlanması ve kullanılması adına pnömatik litotriptör ile taşların $1 \mathrm{~cm}$ altındaki birkaç parçaya ayrıldıktan sonra alınması zaman açısından tasarruf sağlayacaktır. Büyük parçaların alınmasının ardından sistoskopun optiği alınarak sadece dış şaftı bırakılıp kalan milimetrik fragmanlar üstten alta doğru yıkama yöntemi ile temizlenerek kısa zamanda taşsızlık sağlanır. İşlem bittikten sonra, öncelikle mesane kontrollü olarak boşaltılır, direk görüş altında trokar çıkarılarak mesane ön duvardaki açıklığın kapanması gözlenir. Nadiren, eğer açıklığın spontan kapanmayacağı düşünülüyorsa bu açıklıktan 


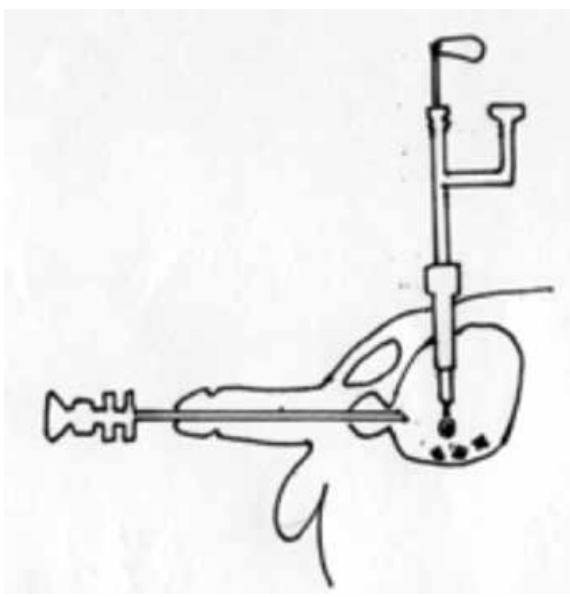

Şekil 2: Sistoskop eşliğinde fragmanların perkütan yolla alınması

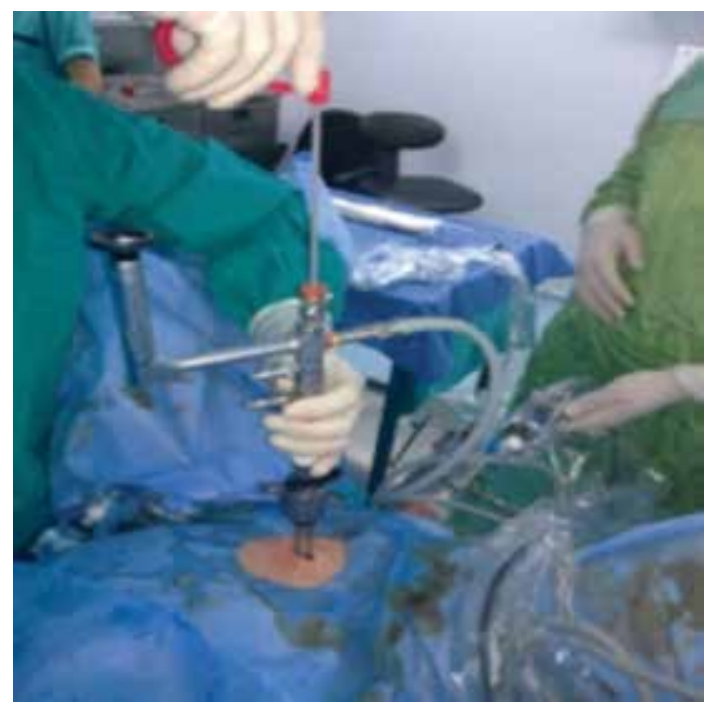

Resim 4: Mesaneden basket ile taş alınması

perkütan sistostomi (2 yollu 16-18 f foley sonda) konabilir. Ardından transüretral 2 yollu foley sonda konularak işlem sonlandırılır. Cilt tek sütür ile kapatılır. Sonda 3 gün sonra alınir.

\section{Sonuçlar}

Bu teknikle vakaların tamamı başarı ile tedavi edilirken; perioperatif herhangi bir sorun yaşanmadi. Ortalama ameliyat süresi 54.4 (20-105) dakika, olup; hasta başına ortalama taş yükü $8.64 \pm 6.55 \mathrm{~cm}^{2}\left(2.35-19.62 \mathrm{~cm}^{2} /\right.$ hasta $)$ idi. Ortalama hastanede kalış ve üretral kateterizasyon süresi $2.22 \pm 1.09$ (1-4) ve 4.11+-1.05 (2-5) gün idi.

Mesane taşı tedavisinin yanı sıra 1 hastaya ileri evre prostat kanseri nedeni ile bilateral skrotal orşiektomi uygulandi. Hastaların tamamında sistostomi gereksinimi olmadan 2 yollu transüretral sonda uyguland. Postoperatif ilk gün hastalar direkt üriner sistem grafisi ve yatakbaşı ultrasonografi ile olası rest kalkül veya üriner ekstravazasyon açısından gözden geçirildi. Rest kalkül görülmedi. Bir hastada hafif perivezikal sıvı koleksiyonu görülmekle birlikte ek bir müda- hale olmadan ultrasonografik kontrollerde 48 saat içinde rezorbe olduğu görüldü. Tüm hastalar sorunsuz taburcu edildi. Kısa dönemde trokar giriş yerinden akıntı veya fistül oluşumu gözlenmedi. Hastaların yaklaşık 2 yıllık (14-28 ay) takiplerinde hiçbirinde alt üriner obstrüksiyon izlenmedi.

\section{Tartışma}

Özellikle son 20 yılda endoskopi ve litotripsi ekipmanlarındaki teknolojik gelişim çoğu mesane taşını transuretral yolla minimal invazif olarak tedavi edilebilir hale getirmiştir. Özellikle çeşitli enerji kaynakları ile etkin fragmantasyon transuretral yöntemi daha çok tercih edilir hale getirmiştir. Ne var ki; transuretral yolla yapılan girişim her zaman kolay olmayabilir. Örneğin çocuk hasta grubunda uretral kalibrasyonun dar olması ve çok ince çaplı endoskoplar gerekmesi bu işlemi zorlaştırır. Bunun yanında büyük ve çok sayıda mesane taşı nedeni ile yapılacak transuretral işlemin süresi, iyatrojenik uretral hasar riski ile birlikte uretral perfüzyon bozukluğuna yol açarak fibroz ve üretral darlık riskini artıracaktır. Her ne kadar işlemin kolaylığı, kısa kateterizasyon süresi ve insizyonsuz olması bu yöntemi günümüzde daha tercih edilir yapsa da uzun dönemdeki risklerin göz önünde bulundurulması gerekir.

Bu mantıkla ilk olarak 1980'lerin sonlarında özellikle; ince enstrumanların bulunmaması nedeniyle açık cerrahiye alternatif olarak, pediatrik yaş grubunda perkütan sistolitotripsi uygulamaları başlamıştır (2-4). Ek olarak çocuk yaşlarda ortaya çıan taş hastalığının orta ve uzun dönem nüks riskinin yüksek olması, tekrarlanabilir alternatif tedavi yöntemlerinin bu yaş grubu için önemini ortaya koymaktadır. Bu ilk vakalarda elde edilen sonuçlar, perkütan yöntemin sadece çocuklara değil diğer yaş gruplarına da uyarlanabileceğini göstermiştir. Uretranın kullanılmayıp mukozal bütünlüğe zarar verilmemesi, ameliyat süresinin kısalığı ve düşük komplikasyon oranları yöntemi popüler hale getirmiştir (5). Aynı zamanda suprapubik yaklaşım yeni rezervuarlarında taş oluşum riski nativ mesaneye göre daha yüksek olan üriner diversiyonlu hastalarda da daha rahat bir yaklaşım olarak göze çarpmaktadır (6). Yöntem aynı zamanda eşlik eden $\mathrm{BPH}$ veya benzeri alt üriner sistem obstrüksiyonu olan hastalarda da; komplikasyon ve operasyon süresini artırmadan eşzamanlı TURP imkanı sağlayabilmektedir (7). Perkütan yöntemin ilk deneyimlerinin başarısı ve benimsenmesinden sonra hasta tercihi ve özellikleri ve uygulayan kliniklerin donanım durumuna göre işlemde çeşitli innovasyonlar yaşanmıştır. Böylece, videoendoskopik görüntü eşliğinde laparoskopik torba kullanarak açı cerrahi gerektiren mesane taşları çıkarılmaya başlanmıştır (8-10). Bizim yöntemimiz endoskopik ve laparoskopik yöntemlerin kombine kullanımı esasına dayanır. Bu yöntemde laparoskopik trokar ile suprapubik yoldan uretral mukozaya zarar vermeden geniş bir perkütan çalışma kanalı oluşturulurken, uretral yolda bulunan ince sistoskop ise işlemin güvenlik altında gerçekleşmesini sağlamaktadır. İşlemde sivri uçlu yeniden kullanılabilir trokar kullanılması tek hamlede dilatasyon ihtiyacı olmaksızın mesaneye giriş imkânı sağlar, floroskopi de gerektirmez. Kesitsel olarak, 10-12 mm'lik trokar, 26 F nefroskopi kıllfına göre daha geniş bir taş çıkarma alanı sağlar. Bu çoğu taşın fragmantasyona ihtiyaç duymadan "en bloc" olarak kısa zamanda çıarılmasına neden olur. Videoendoskopik görüntü ve transilüminasyon altında güvenli giriş, kanlanması 
oldukça fazla olan mesane duvarında minimal hemorajiye sebep olur. Yeterli mesane dolumu ile alt abdominal bölge cerrahisi geçirmiş hastalarda bile güvenli bir giriş sağlanabilir. Küçük çaplı bir sistoskopun kullanılması uretral hasarı minimuma indirger. Trokar ve nefroskopun girilmesi ile grasper ve basket ile taşların alınması veya alınabilecek seviyeye indirgenmesi artık kolaydır. Lazer veya diğer yöntemlerle milimetrik fragmanlar haline getirilebilinirse de; bu zaman kaybına neden olabilir. Taşların mümkün olduğunca bütün olarak alınması zaman tasarrufu sağlar. Teknik gerek hazırlık gerekse uygulama açısından her bir uroloğu zaten aşina olduğu pratikleri birleştirdiğinden öğrenme eğrisini kısalığ1 ve kolaylığı dikkat çekicidir. Uzun dönemde elde edilen bilgiler uretral darlık oranlarının transuretral girişimlere göre daha az olacağı yönündedir. Daha önce mesane kanseri olanlarda, aktif üriner ve karın duvarı enfeksiyonu olanlarda kontraendike olmakla birlikte geçirilmiş batın cerrahisi ve radyoterapi hikayesi olanlarda deneyimle paralel olarak işlem yapılabilir.

Sonuç olarak videosistoskopik görüntü eşliğinde laparoskopik trokarla yapılan perkütan yaklaşım öğrenme eğrisi kısa, uygulaması kolay bir yöntemdir. Uygun hazırlık ve ilk deneyimler sonrası işlem oldukça kısa zamanda sonuçland1rılabilmektedir. Özellikle büyük ve çok sayıda mesane taşı olan hastalarda uzun dönemde uretral hasar riskini azaltmak adına iyi bir alternatif yöntem olduğunu düşünmekteyiz. $\mathrm{Bu}$ yöntem ile ilgili bir diğer önemli çıkarım ise endoüroloji ile ilgilenen ürologlar için değişik yöntemlerin birbirlerinin rakibi veya alternatifi değil, tamamlayıcısı olduğunun hatırlanmasıdır. Sistoskopi ve laparoskopinin birleşimi buna güzel bir örnektir. Bir diğer örneğini endoskopik kombine intrarenal cerrahi'de (ECIRS) gördüğümüz bu yaklaşım muhtemelen ileri dönemlerde daha popüler olacaktır.

\section{Kaynaklar}

1. Schwartz BF, Stoller ML. The vesicle calculus. Urol Clin North Am 2000; 27: 333-345.
2. Gopalakrishnan G, Bhaskar P, Jehangir E. Suprapubic lithotripsy. Br J Urol 1988; 62: 389-392.

3. Badlani GM, Douenias R, Smith AD. Percutaneous bladder procedures. Urol Clin North Am 1990; 17: 67-73.

4. Agrawal MS, Aron M, Goyal J, Elhence IP, Asopa HS. Percutaneous suprapubic cystolithotomy for vesical calculi in children. J Endourol 1999; 13: 173-175.

5. Demirel F, Çakan M, Yalçınkaya F, Demirel AC, Aygün A, Altuğ UU. Percutaneous suprapubic cystolithotripsy approach: For whom? Why? J Endourol 2006; 20: 29-431.

6. Lam PN, Te CC, Wong C, Kropp BP. Percutaneous cystolithotomy of large urinary-diversion calculi using combination of laparoscopic and endourologic techniques. J Endourol 2007; 21: 155-157.

7. Aron M, Goel R, Gautam G, Seth A, Gupta NP. Percutaneous versus transurethral cystolithotripsy and TURP for large prostates and vesical calculi: Refinement of technique and updated data. Int Urol Nephrol 2007; 39: 173-177.

8. Batislam E, Germiyanoğlu C, Karabulut A, Berberoğlu M, Nuhoğlu B, Gülerkaya B, Erol D. A new application of laparoscopic instruments in percutaneous bladder stone removal. J Laparoendosc Adv Surg Tech A 1997; 7: 241244.

9. Ramalingam M, Selvarajan K, Senthil K. A novel technique of cystolithotripsy for large vesical calculus in children. Ped Endosurg Innov Tech 2003; 7: 333-337.

10. Segarra J, Palou J, Montlleó M, Salvador J, Vicente J. Hansson's laparoscopic trocar in percutaneous bladde $r$ stone lithotripsy. Int Urol Nephrol 2001; 33: 625-626.

Yazışma Adresi:

Erkan Erkan

İstanbul Eğitim ve Araştırma Hastanesi, Üroloji Kliniğgi, Org. Nafiz Gürman Caddesi, 34098 Fatih, İstanbul

Tel: +90 2124596130

e-mail:drerkanerkan@yahoo.com 